\title{
STRATEGI PEMASARAN KERUPUK MANGGA PADA INDUSTRI RUMAH TANGGA LIBNA FOOD
}

\author{
Dody Iskandar ${ }^{1}$, Entus Hikmana ${ }^{2}$, Neneng Sri Mulyati ${ }^{3}$ \\ 1,2,3 Program Studi Agribisnis, Fakultas Pertanian, Universitas Wiralodra \\ Email : iskandardody266@gmail.com를 entushikmana@gmail.com², nenengsrimulyati44@gmail.com ${ }^{3}$
}

\begin{abstract}
ABSTRAK
Penelitian bertujuan untuk mengetahui rumusan faktor internal dan faktor eksternal yang terdiri dari kekuatan, kelemahan, peluang, ancaman dan strategi pemasaran kerupuk mangga pada Industri Rumah Tangga Libna Food Desa Jatisura Kecamatan Cikedung Kabupaten Indramayu. Metode penelitian yang digunakan adalah metode survei dan desain penelitian menggunakan survei deskriptif. Penelitan ini tidak di lakukan pengambilan sampel dari populasi karena populasi Industri Rumah Tangga kerupuk dengan bahan baku mangga hanya satu orang, yaitu Industri Rumah Tangga Libna Food yang memproduksi kerupuk. Jenis data yang digunakan dalam penelitian yaitu data primer dan data skunder. Teknik pengumpulan data melalui studi pustaka, observasi, dan wawancara. Data yang diperoleh selanjutnya dianalisis menggunakan analisis SWOT dan QSPM. Hasil menunjukan bahwa usaha kerupuk mangga pada Industri Rumah Tangga Libna Food Desa Jatisura Kecamatan Cikedung Kabupaten Indramayu berdasarkan hasil perhitungan, nilai bobot dan rating (BxR) keseluruhan nilai pada faktor internal (IFAS) total sebesar 2,28. Sedangkan dari hasil perhitungan nilai bobot dan rating $(\mathrm{BxR})$ dapat dihasilkan keseluruhan jumlah bobot total sebesar 2,14. untuk faktor eksternal (EFAS), yang artinya perusahaan berada pada posisi (hold and maintain) yang terletak pada kuadran V. Hal ini mennjukkan bahwa perusahaan membutuhkan strategi untuk bertahan dan dapat menjaga perusahaan menjadi lebih baik lagi. Maka dari itu analisis SWOT diperoleh beberapa strategi yang terdapat pada kuadran $\mathrm{V}$ yang nantinya akan menjadi prioritas strategi yang tepat untuk dilaksanakan terlebih dahulu dengan menggunakan analisis QSPM.
\end{abstract}

Kata Kunci : Analisis SWOT, Kerupuk mangga, QSPM, Strategi Pemasaran.

\section{PENDAHULUAN}

Mangga merupakan salah satu komoditas unggulan khas Jawa Barat, yang sentra produksinya relatif terpusat di Wilayah Cirebon, Indramayu, Majalengka,Kuningan, dan Sumedang. Potensi tanaman mangga di Indramayu sudah tidak asing lagi bagi masyarakat sekitar, hampir setiap rumah memiliki tanaman tersebut (Setia, 2018). Meski demikian perkebunan tanaman mangga salah satu-nya terdapat di Desa Jatisura Kecamatan Cikedung Kabupaten Indramayu. Indramayu mempunyai potensi yang baik untuk menghasilkan buah mangga, terlihat dari produksi mangga, luas panen tanaman mangga, dan produktivitas dari Data BPS Indramayu seperti ditunjukkan pada Tabel 1.

Berdasarkan Tabel 1, buah mangga merupakan komoditas unggulan di Kabupaten Indramayu. Jumlah produksi mangga dari tahun 2012 sampai tahun 2014 terjadi kenaikan yang cukup besar mencapai 1.156.366 Kw, akan tetapi pada tahun 2015 mengalami penurunan sampai $712.818 \mathrm{Kw}$. Kemudian pada tahun 2016 kembali Mengalami penurunan yang sangat signifikan mencapai $143.614,82 \mathrm{Kw}$. 


\begin{tabular}{cccc}
\hline \multicolumn{2}{c}{ Tabel 1. Luas Panen, Produktivitas dan Produksi Mangga di Kabupaten Indramayu Tahun 2012- 2016 } \\
\hline \multirow{2}{*}{ Tahun } & $\begin{array}{c}\text { Luas Panen } \\
\text { (Pohon) }\end{array}$ & $\begin{array}{c}\text { Jumlah Produksi Mangga } \\
(\text { Kw) }\end{array}$ & $\begin{array}{c}\text { Jumlah Produktivitas } \\
\text { (Kw/Pohon) }\end{array}$ \\
\hline 2012 & 577.865 & 685.177 & 1,19 \\
2013 & 660.147 & 847.878 & 1,28 \\
2014 & $1.153,176$ & 1.156 .366 & 1,00 \\
2015 & 491.494 & $712.817,96$ & 1,45 \\
2016 & 575.234 & $143.614,82$ & 2,50 \\
\hline
\end{tabular}

Sumber : Badan Pusat Statistik (2017).

Salah satu jenis mangga yang sudah diproduksi secara intensif di Desa Jatisura Kecamatan Cikedung Kabupaten Indramayu adalah jenis Mangga Gedong Gincu, karena jenis varietas mangga tersebut sangat bagus untuk diolah menjadi makanan seperti Kerupuk Mangga. Mayoritas masyarakat di desa tersebut bekerja sebagai petani padi dan mangga dikarenakan Desa Jatisura memiliki kesuburan tanah yang baik untuk tanaman padi maupun mangga. Maka dari itu masyarakat

Sekitar terus mencoba untuk memanfaatkan kekayaan dan keanekaragaman sumber daya alam yang berpotensi di Desa Jatisura Kecamatan Cikedung Kabupaten Indramayu, Berikut ini data produksi Mangga Gedong Gincu di Kecamatan Cikedung Kebupaten Indramayu. Berdasarkan Tabel 2, bahwa produksi Mangga Gedong Gincu dari tahun 2014 mengalami kenaikan yang cukup besar. Sedangkan Pada tahun 2015 sampai 2016 terjadi penurunan hasil produksi mencapai 2.588,44 Kw.kemudian di tahun 2017 kembali naik ke angka 17.806,383 Kw.

Tabel 2. Produksi Mangga Gedong Gincu di Kecamatan Cikedung Kabupaten Indramayu Tahun 2013-2017

\begin{tabular}{ccr}
\hline No. & Tahun & Produksi Mangga Gedong Gincu (Kw) \\
\hline 1. & 2013 & $18.928,25$ \\
2. & 2014 & $23.896,00$ \\
3. & 2015 & $13.082,00$ \\
4. & 2016 & $2.588,44$ \\
5. & 2017 & $17.806,383$ \\
\hline
\end{tabular}

Sumber : Dinas Pertanian Indramayu (2018)

Analisis SWOT adalah salah satu metode identifikasi berbagai faktor secara sistematis untuk merumuskan strategi perusahaan. Analisis ini didasarkan pada logika yang dapat memaksimalkan kekuatan (Strength), dan peluang (Opportunity), namun secara bersamaan dapat meminimalkan kelemahan (Weakness), dan ancaman (Threat) (Rangkuti, 2015). Berdasarkan latar belakang tersebut, peneliti tertarik dengan masalah mengenai Strategi Pemasaran Kerupuk Mangga (Mangifera indica, L.) pada Industri Rumah Tangga Libna Food Desa Jatisura Kecamatan Cikedung Kabupaten Indramayu Tahun 2018.

\section{Tujuan Penelitian}

Penelitian ini bertujuan untuk mengetahui kekuatan, kelemahan, peluang, dan ancaman dalam usaha Kerupuk Mangga pada Industri Rumah Tangga Libna Food Desa Jatisura Kecamatan Cikedung Kabupaten Indramayu dan memperoleh strategi yang tepat bagi pemasaran Kerupuk Mangga pada Industri Rumah Tangga Libna Food Desa Jatisura Kecamatan Cikedung Kabupaten Indramayu.

\section{METODE PENELITIAN}

\section{Lokasi dan Jadwal Penelitian}

Penelitian ini dilakukan pada Industri Rumah Tangga Libna Food di Desa Jatisura Blok Masjid RT/RW 03/03 Kecamatan Cikedung Kabupaten Indramayu. Penelitian ini dilaksanakan dari bulan September 2018 sampai dengan Agustus 2019. 


\section{Metode Pengumpulan Data}

Desain penelitian yang digunakan dalam penelitian ini adalah survei deskriptif. Survei deskriptif digunakan untuk membuat deskripsi, gambaran/lukisan secara sistematis, faktual dan akurat mengenai fakta-fakta, sifat-sifat, serta hubungan fenomena yang diselidiki (Nazir, 1988). Jenis dan sumber data yang digunakan dalam penelitian ini adalah data primer dan data sekunder. Data primer merupakan data yang diambil dan diolah sendiri oleh peneliti atau data yang secara langsung dikumpulkan sendiri oleh perorangan atau suatu organisasi melalui objeknya (Supranto, 2003).

\section{Metode Penentuan Sampel}

Penelitian ini tidak dilakukan pengambilan sampel dari populasi, karena populasi industri rumah tangga kerupuk dengan bahan baku dari mangga hanya satu orang yaitu Industri Rumah Tangga Libna Food di Desa Jatisura Kecamatan Cikedung Kabupaten Indramayu. Sehingga sampel dan populasinya sama yaitu satu orang.

\section{Analisis Data}

Penyusunan strategi dilakukan melalui tiga tahap analisis, yaitu tahap pengumpulan data dengan menentukan faktor lingkungan internal dan eksternal, tahap analisis (analisis SWOT, analisis IFAS dan EFAS, dan analisis matrik IE), dan tahap pengambilan keputusan dengan menggunakan Quantitative Strategic Planning Matrix (QSPM).

\section{HASIL DAN PEMBAHASAN}

\section{Analisis Faktor Internal dan Eksternal}

Analisis ini dilakukan untuk mengetahui faktor-faktor apa saja yang mempengaruhi keberhasilan pemasaran suatu usaha. Faktor lingkungan internal terdiri dari kekuatan (strength) dan kelemahan (weakness). Sedangkan faktor lingkungan eksternal terdiri dari peluang (opportunity) dan ancaman (threat). Maka faktor internal dan eksternal dalam penelitian ini yaitu sebagai berikut.

\section{Analisis SWOT}

Berdasarkan faktor SWOT dalam menganalisis lingkungan internal dan eksternal maka dilakukan perpaduan antara kekuatan, kelemahan, peluang dan ancaman dengan matriks IFAS dan EFAS, Matriks Grand Strategy (Matrik Internal Eksternal/IE) dan Matriks SWOT. Bertujuan untuk menentukan strategi alternatif yang dipilih. Menggambarkan secara jelas mengenai kekuatan dan kelemahan internal dengan menyelaraskan peluang dan ancaman eksternal. Sebagai bahan pertimbangan dalam pemasaran kerupuk mangga. Beberapa strategi alternatif sebagai bahan pertimbangan dalam pemasaran kerupuk mangga di Kabupaten Indramayu. Analisis matrik SWOT tersebut menghasilkan 4 (empat) komponen strategi yaitu (1) Strategi S-O (Strength-Opportunities); (2) Strategi W-O (Weakness-Opportunities); (3) Strategi S-T (Strenght-Thrests); dan (4) Strategi W-T (Weakness-Threats). Komponen strategi yang diperoleh dari analisis matrik SWOT dapat dilihat pada Tabel 2.

Tabel 3. Faktor-faktor Lingkungan Internal dan Eksternal

\section{Faktor Lingkungan Internal}

\section{Kekuatan (Strengths)}

1. Produk memiliki cita rasa yang khas

2. SDM yang tersedia

3. Harga jual terjangkau

4. Tanpa bahan pengawet

5. Produk yang dihasilkan merupakan hasil olahan dari buah mangga yang bahan bakunya tersedia

\section{Faktor Lingkungan Eksternal}

\section{Peluang (Opportunities)}

1. Belum ada pesaing usaha

2. Jangkauan pasar masih tebuka luas

3. Diversifikasi produk

4. Adanya dukungan dari lingkungan di sekitar tempat usaha

5. Potensi daerah yang mendukung dalam pelaksanaan produksi 
Faktor Lingkungan Internal

\section{Kelemahan (Weaknesses)}

1. Ketersediaan modal terbatas

2. Produk mudah rusak

3. Pengemasan masih sederhana

4. Pemasaran masih terbatas

5. Konsumen masih belum mengetahui produk kerupuk mangga

6. Peralatan yang digunakan dalam produksi masih sederhana

\section{Faktor Lingkungan Eksternal}

\section{Ancaman (Threats)}

1. Belum adanya dukungan dari pihak tertentu dalam pemodalan

2. Ketersediaan bahan baku yang musiman

3. Belum terdaftar dan belum mendapat dukungan dari pemerintah dalam perizinan dan pengembangan usaha

4. Tempat penjualan kurang strategis

\section{Analisis IFAS dan EFAS}

Berdasarkan analisis lingkungan internal dan eksternal, dilakukan perhitungan analisis IFAS (Internal strategic Factor Analysis Summary) dan EFAS (Eksternal strategic Factor Analysis Summary).Hasil yang diperoleh dari Matrik IFAS (Tabel 3) nilai indeks kumulatif untuk elemen kekuatan sebesar 1,12 dan elemen kelemahan sebesar 1,16. Hal tersebut menunjukkan bahwa pengusaha kerupuk mangga di Kabupaten Indramayu memberikan respon tinggi terhadap faktor kelemahan dan memberikan respon rendah terhadap faktor kekuatan. Total skor IFAS (Internal strategic Factor Analysis Summary) sebesar 2,28. Sedangkan hasil yang diperoleh dari matrik EFAS pada Tabel 2 yaitu nilai indeks kumulatif skor peluang sebesar 1,40 dan skor untuk elemen ancaman sebesar 0,74. Hal ini menunjukkan bahwa pengusaha kerupuk mangga di Kabupaten Indramayu memberikan respon yang tinggi terhadap faktor peluang dan respon yang rendah terhadap faktor ancaman. Total skor EFAS (Eksternal strategic Factor Analysis Summary) sebesar 2. 
Tabel 4. Matrik Analisis SWOT pada Industri Rumah Tangga Libna Food

\begin{tabular}{|c|c|c|}
\hline Intern & Kekuatan (S) & Kelemahan (W) \\
\hline & $\begin{array}{l}\text { 1. Produk memiliki cita } \\
\text { rasa yang khas. } \\
\text { 2. SDM yang tersedia } \\
\text { 3. Harga jual terjangkau } \\
\text { 4. Tanpa bahan pengawet. } \\
\text { 5. Produk yang dihasilkan } \\
\text { merupakan olahan dari buah } \\
\text { mangga yang bahan } \\
\text { bakunya tersedia. }\end{array}$ & $\begin{array}{l}\text { 1. Ketersediaan modal terbatas. } \\
\text { 2. Produk mudah rusak } \\
\text { 3. Pengemasan masih sederhana. } \\
\text { 4. Pemasaran masih terbatas. } \\
\text { 5. Konsumen masih belum mengetahui } \\
\text { produk kerupuk mangga. } \\
\text { 6. Peralatan dalam proses produksi } \\
\text { masih sederhana. }\end{array}$ \\
\hline Peluang (O) & Strategi (S-O) & Strategi (W-O) \\
\hline 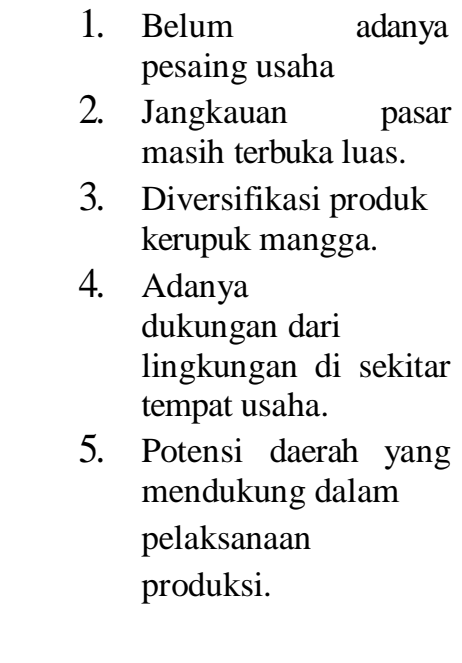 & $\begin{array}{l}\text { 1. Meningkatkan kualitas rasa } \\
\text { kerupuk mangga dalam } \\
\text { memanfaatkan potensi dan } \\
\text { peluang pasar yang masih } \\
\text { terbuka. (S2-O2) } \\
\text { 2. Membuat produk } \\
\text { kerupuk mangga lebih } \\
\text { beragam dan tidak } \\
\text { meninggalkan cita rasa yang } \\
\text { khas sehingga konsumen } \\
\text { memiliki banyak pilihan } \\
\text { rasa dalam rangka meraih } \\
\text { pangsa pasar yang lebih } \\
\text { luas.(S1-O2,03) } \\
\text { 3emanfaatkan SDM yang } \\
\text { terampil dan }\end{array}$ & $\begin{array}{l}\text { 1. Mengembangkan produk dengan } \\
\text { membuat kerupuk manga dalam } \\
\text { berbagai varian rasa dengan kemasan } \\
\text { yang lebih menarik dan ukuran yang } \\
\text { beragam agar dapat menjangkau } \\
\text { pasar yang lebih luas (W2, W3, O2, } \\
\text { O3) } \\
\text { 2. Memanfaatkan dukungan lingkungan } \\
\text { sekitar untuk mensosialisasikan } \\
\text { kerupuk mangga dan } \\
\text { meningkatkan promosi. } \\
\text { 3. Bekerjasama dengan lembaga } \\
\text { permodalan untuk meningkatkan } \\
\text { produksi dengan memafaatkan } \\
\text { potensi daerah yang ada dan } \\
\text { peralatan produk yang lebih modern. }\end{array}$ \\
\hline
\end{tabular}

menjalin kerjasama dengan stakeholder
setempat, dalam rangka meraih produktivitas usaha yang tinggi. (S2- 05) 


\section{Ancaman (T)}

1. Belum ada dukungan dari pihak tertentu dalam hal permodalan.

2. Ketersediaan bahan baku yang musiman.

3. Belum terdaftar dan belum mendapat dukungan dari pemerintah dalam perizinan dan pengembangan usaha.

4. Tempat penjualan kurang strategis.

\section{Strategi (S-T)}

1. Menjaga kekuatan cita rasa yang khas dan Mencari lokasi pasar yang lebih strategis dan untuk memperkenalkan produk agar lebih mudah. (S1-T4)

2. meningkatkan manajemen SDM produksi yang baik dan Melakukan komunikasi dengan pemerintah setempat agar mendapat dukungan demi keberlangsungan usaha.(S2-T3)

\section{Strategi (W-T)}

1. Bekerjasama dengan pihak instansi terkait untuk memperluas jangkauan pasar. (W4-T3)

2. Memperluas jangkauan pasar dengan memilih lokasi pemasaran yang lebih strategis.(W4-T4)

3. Menggunakan teknologi produksi yang lebih modern dan bekerjasama dengan petani mangga yang melakukan budidaya secara offseason untuk mengatisipasi ketersediaan bahan baku.(W6-T2)

Tabel 5. Matrik IFAS (Internal strategy Factor Analysis Summary)

\begin{tabular}{|c|c|c|c|c|}
\hline \multirow{2}{*}{ No. } & \multirow{2}{*}{ Komponen Faktor Internal } & \multirow{2}{*}{$\begin{array}{c}\text { Bobot } \\
\text { (B) }\end{array}$} & \multirow{2}{*}{$\begin{array}{l}\text { Rating } \\
(\mathbf{R})\end{array}$} & Skor \\
\hline & & & & $(\mathbf{B} \times \mathbf{R})$ \\
\hline \multicolumn{5}{|c|}{ Kekuatan } \\
\hline 1. & Produk memiliki cita rasa yang khas & 0,10 & 3 & 0,29 \\
\hline 2. & SDM yang tersedia & 0,10 & 3 & 0,19 \\
\hline 3. & Harga jual terjangkau & 0,11 & 2 & 0,22 \\
\hline 4. & $\begin{array}{l}\text { Tanpa bahan pengawet } \\
\text { produk yang dihasilkan merupakan hasil }\end{array}$ & 0,08 & 3 & 0,23 \\
\hline 5. & $\begin{array}{l}\text { olahan dari buah mangga yang } \\
\text { bahan bakunya tersedia }\end{array}$ & 0,09 & 2 & 0,17 \\
\hline \multicolumn{2}{|r|}{ Total } & \multicolumn{3}{|r|}{1,12} \\
\hline \multicolumn{5}{|c|}{ Kelemahan } \\
\hline 1. & Ketersediaan modal terbatas & 0,12 & 2 & 0,24 \\
\hline 2. & Produk mudah rusak & 0,05 & 3 & 0,15 \\
\hline 3. & Pengemasan masih sederhana & 0,06 & 2 & 0,13 \\
\hline 4. & Pemasaran masih terbatas & 0,11 & 2 & 0,22 \\
\hline 5. & $\begin{array}{l}\text { Konsumen masih belum mengetahui } \\
\text { produk kerupuk mangga }\end{array}$ & 0,13 & 2 & 0,26 \\
\hline 6. & $\begin{array}{l}\text { Peralatan dalam produksi masih } \\
\text { Sederhana }\end{array}$ & 0,05 & 3 & 0,16 \\
\hline \multicolumn{4}{|c|}{$\begin{array}{l}\text { Total } \\
\end{array}$} & 1,16 \\
\hline & Akumulasi Skor IFAS & & & 2,28 \\
\hline
\end{tabular}


Tabel 6. Matrik EFAS (Eksternal strategy Factor Analysis Summary)

\begin{tabular}{|c|c|c|c|c|}
\hline No & Komponen Faktor Esternal & Bobot & Rating & Skor \\
\hline \multicolumn{5}{|c|}{ Peluang } \\
\hline 1. & Belum adanya pesaing usaha & 0,13 & 3 & 0,40 \\
\hline 2. & Jangkauan pasar masih luas & 0,12 & 3 & 0,36 \\
\hline 3. & diversifikasi produk & 0,06 & 3 & 0,19 \\
\hline & $\begin{array}{l}\text { Adanya dukungan dari lingkungan di sekitar tempat } \\
\text { Usaha }\end{array}$ & 0,09 & 2 & 0,17 \\
\hline & $\begin{array}{l}\text { Potensi daerah yang mendukung dalam pelaksanaan } \\
\text { Produksi }\end{array}$ & 0,09 & 3 & 0,28 \\
\hline & Total & & & $\mathbf{1 , 4 0}$ \\
\hline \multicolumn{5}{|c|}{ Ancaman } \\
\hline & $\begin{array}{l}\text { Belum adanya dukungan dari pihak tertentu dalam } \\
\text { hal permodalan }\end{array}$ & 0,15 & 2 & 0,30 \\
\hline 2. & bahan baku musiman & 0,11 & 1 & 0,11 \\
\hline 3. & $\begin{array}{l}\text { Belum terdaftar dan belum mendapat dukungan dari } \\
\text { pemerintah dalam perizinan dan pengembangan } \\
\text { Usaha }\end{array}$ & 0,09 & 2 & 0,17 \\
\hline 4. & Tempat penjualan kurang strategis & 0,16 & 1 & 0,16 \\
\hline & Total & & & $\mathbf{0 , 7 4}$ \\
\hline & Akumulasi Skor EFAS & & & 2,14 \\
\hline
\end{tabular}

Analisis Matrik IE dan Analisis Quantitative Strategic Planning Matrix (QSPM)

Matriks IE merupakan matrik perpaduan antara variabel IFAS (Intenal strategy Factor Analysis Summary) dengan variabel EFAS (Ekstenal Strategi Factor Analysis Summary). Strategi dapat di terapkan setelah diketahui posisi usaha kerupuk mangga di Desa Jatisura Kecamatan Cikedung dalam matriks Internal Eksternal (IE). Tujuannya untuk memperoleh strategi dalam pemasaran usaha tersebut, melihat posisi dan arah perkembangan selanjutnya. Titik temu antara total skor IFAS dan dengan total skor EFAS dapat dilihat pada Gambar 1.

Berdasarkan hasil dari matriks IFE dan matriks EFE maka dapat disusun selanjutnya dalam matriks IE. Nilai IFE sebesar 2,28. dan EFE sebesar 2,14. Nilai IFE dan EFE diperoleh dari jumlah dari skor pada masing- masing faktor, di mana skor tersebut diperoleh dari perkalian antara rata-rata rating dan rata-rata bobot pada masing-masing faktor serta diperoleh nilai matrik menunjukkan pada posisi kuadran $\mathrm{V}$. 


\section{Skor Total IFAS}

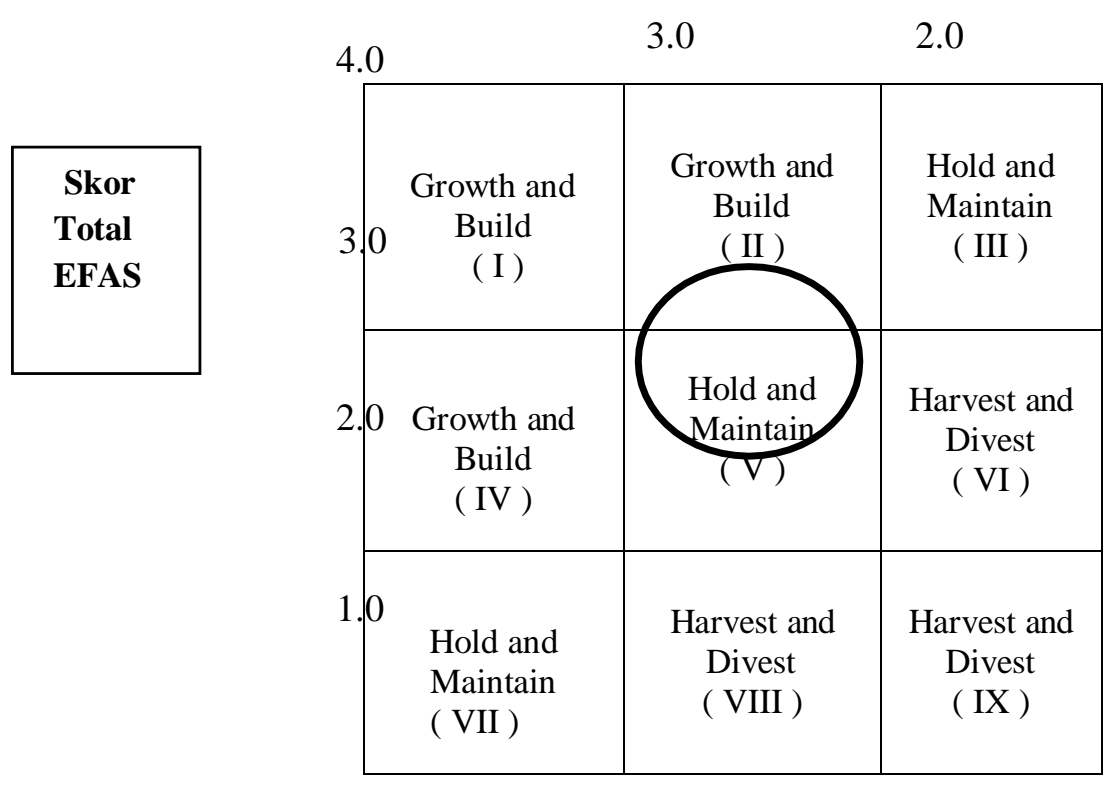

1.0

Gambar 1. Matrik IE

Sumber : David (2006).

\section{SIMPULAN DAN SARAN}

Berdasarkan pembahasaan yang sudah diuraikan, maka kesimpulan dalam penelitian ini adalah sebagai berikut :

1. Faktor Internal dan Eksternal yang menjadi kekuatan, kelemahan, peluang, dan ancaman yang ada dalam pemasaran kerupuk mangga pada Industri Rumah Tangga Libna food, antara lain adalah :

- Kekuatan antara lain: a) Produk memiliki cita rasa yang khas; b) SDM yang tersedia; c) Harga jual terjangkau; d) Tanpa bahan pengawet; e) Produk yang dihasilkan merupakan hasil olahan dari buah mangga yang bahan bakunya tersedia.

- Kelemahan dalam usaha ini antara lain: a) Ketersediaan modal terbatas; b) Produk mudah rusak; c) Pengemasan masih sederhana; d) Pemasaran masih terbatas; e) konsumen masih belum mengetahui produk kerupuk mangga; dan f) Peralatan yang digunakan dalam proses produksi masih sederhana.

- Peluang dalam usaha ini antara lain: a) Belum adanya pesaing usaha; b)Jangkauan pasar masih terbuka luas; c) diversifikasi produk; d) Adanya dukungan dari lingkungan di sekitar tempat usaha; dan e) Potensi daerah yang mendukung dalam pelaksanaan produksi.

- Ancaman dalam usaha ini antara lain: a) Belum ada dukungan dari pihak tertentu dalam permodalan; b) ketersediaan bahan baku yang bersifat musiman; c) Belum adanya

dukungan dari pemerintah atau instansi yang berkaitan dengan usaha kerupuk mangga; d) Tempat penjualan kurang strategis.

2. Strategi yang dihasilkan dalam penelitian ini yakni strategi W-O (Weakness and Opportunity), dengan prioritas strategi yang dapat dilaksanakan yaitu memanfaatkan dukungan lingkungan sekitar untuk mensosialisasikan kerupuk mangga dan meningkatkan promosi. 


\section{Saran}

Berdasarkan simpulan dalam penelitian ini dapat disarankan hal-hal sebagai berikut :

1) Pengusaha diharapkan untuk membuat kemasan yang semenarik mungkin agar minat konsumen untuk membeli tinggi.

2) Diperlukan adanya kerjasama dengan pemasok bahan baku dan lembaga permodalan.

3) Tetap menjaga kualitas bahan baku sehingga menghasilkan produk yang berkualitas, tentunya dengan tidak pernah menggunakan bahan pengawet.

4) Selalu berkomunikasi dengan masyarakat sekitar untuk menjaga hubungan baik agar usaha kerupuk mangga tetap mendapat dukungan dan kepercayaan dari masyarakat.

5) Membuat produk dengan berbagai varian rasa contohnya : dengan rasa pedas, balado. Namun tidak mengubah komposisi faktor produksi.

\section{Ucapan Terimakasih}

Ucapan Terimaksih saya ucapkan kepada pihak terkait dalam penelitian ini baik eksternal maupun internal yang telah membantu penelitian .

\section{DAFTAR PUSTAKA}

Assauri, Sofyan. 2005. Manajemen Pemasaran Produksi dan Operasi.

Badan Pusat Statistik. 2017. Ketenagakerjaan. Indramayu. 2017. Cikedung Dalam Angka. Indramayu.

David, Fred R. 2006. Manajemen Strategi. Penerbit Salemba Empat, Jakarta.

Dinas Pertanian Kebupaten Indramayu. 2018. Produksi Mangga Gedong Gincu Kecamatan Cikedung.

Emma S. Wirakusuma, 1994. Buah Dan Sayur Untuk Terapi. Penebar- Suwadaya. Jakarta.

Gitosudarmo, Indriyo, 2000. Manajemen pemasaran. Edisi II BPFE, Yogyakarta.

Idat, Entus Hikmana. 2016. Manajemen Strategi Kebijakan Bisnis, Menuju Pengembangan Bisnis yang Berkelanjutan dan Ramah Lingkungan. Penerbit: K- Media.Yogyakarta.

Koswara, Sutrisno. 2009. Pengolahan Aneka Kerupuk. Jakarta. Gramedia.

Kotler dan Keller. 2009. Marketing Manajemen. Erlangga. Jakarta.

Kotler, Philip. 1997. Manajemen pemasaran. Edisi Bahasa Indonesia jilid satu. Prentice Hall. Jakarta. 2005.

Manajemen pemasaran. Jilid 1 dan 2: PT Indeks Kelompok Gramedia. Jakarta. 2009. Marketing. Ahli Bahasa: Herujati Purwoko. Erlangga. Jakarta.

Nazir, M. 1988. Metode Penelitian, Ghalia Indonesia. Jakarta.

Pracaya. 2011. Bertanama Mangga. Penebar Suwadaya : Jakarta.

Radiosunu, 1983, Manajemen Pemasaran (Suatu Pendekatan Analisis), BPFE, Yogyakarta.

Rangkuti, F. 2009. Analisis SWOT Teknik Membedah Kasus Bisnis. PT.Gramedia Pustaka Utama. Jakarta. 2011. SWOT Balance Scorecard Teknik Menyusun Strategi Korporat Yang Efektif Plus Cara Mengelola Kinerja Dan Resiko. PT . Gramedia Pustaka Utama. Jakarta. 2015. Analisis 
SWOT: Teknik Membedah Kasus Bisnis Cara Perhitungan Bobot, Rating, dan OCAL. Penerbit PT. Gramedia Pustaka Utama : Jakarta.

Rismaya, Evie. 2016. Strategi Pemasaran Kerupuk Ikan Tenggiri Produksi Karida desa Tambak, Kecamatan Indramayu Kabupaten Indramayu. Skripsi, Program Studi Agribsnis Fakultas Pertanian Universitas Wiralodra Indramayu.

Rukmana, R. 1997. Mangga : Budidaya Pasca Panen. Kanisius. Yogyakarta.

Rusliaty, T \& Zulhipri. 2012. Kandungan Gizi Biji Mangga Indramayu (Mangifera indica, L.) Jaringan Buah mangga (Mangifera indica L) Var Gedong Gincu pada berbagai suhu Penyimpanan. Jurnal Kompetensi Teknik Vol. 2. No.1, November 2010.

Setia, Hadi. 2018. Strategi Pemasaran Dodol Mangga Gedong Gincu (mangifera indica, L.) pada UKM Listatin Kasturi Buah harum Sari desa Pawidean Kecamatan Jatibarang Kabupaten Indramayu, Skripsi Program Studi Agribsnis Fakultas Pertanian Universitas Wiralodra Indramayu.

Singarimbun, Masri Dan Effendi Sofian. 1985. Metode Penelitian Survey. LP3ES. Jakarta.

Soekartawi. 1999. Agribisnis teori dan aplikasi. PT. Raja Grafindo Persada.

Sugiyono. 2010. Metode Penelitian Pendidikan Pendekatan Kuantitatif, Kualitatif, dan R\&D. Alfabeta : Bandung.

Sumarni, Murti dan John Soeprihanto. 2010. Pengantar Bisnis (Dasar-dasar Ekonomi Perusahaan). Edisi kelima. Penerbit Libert. Yogyakarta.

Supranto, J. 2003. Metode Riset Aplikasinya Dalam Pemasran. Rineka Cipta. Jakarta.

Tafajani. D. S. 2011. Panduan Komplit Bertanam Sayur Dan Buah-Buahan. Yogyakarta : Cahaya Atma. UNDIP Semarang, Erlangga. Jakarta. 